\title{
Body Language Classification and Communicative Context
}

\author{
Jianxue Yin \\ Nanyang Institute of Technology \\ Nanyang, Henan, China, 473004 \\ e-mail: yinjianxve@sina.com
}

\begin{abstract}
Body language is visual signals used in people's social intercourse which include movements, postures, and facial expressions that communicate emotions, attitudes and auxiliary information. Body language can be classified into symbolic body language and physiological body language according to its property; dynamic body language and static body language according to the state of the participator in social intercourse; auxiliary body language and independent body language according to its functions; and body language for specific occasions and body language for regular occasions according to the occasion where it is used. Understanding body language can not be achieved without the communicative context. Communicative context of body language includes posture group, linguistic context and social context.
\end{abstract} Context

Keywords-Body Language; Classification; Communicative

\section{About Body Language}

There are different names of body language, such as "gesture language", "posture language", "human body language", and "action language", etc. People also have different understandings of body language, the most typical of which says "people communicate with each other not only by voicing verbal language, but also by making eye contact, hand gestures, facial expressions, body movements, wearing different clothes and makeup, and maintaining distance. These non-linguistic symbols will complement linguistic symbols by stressing, confirming, negating or weakening the meaning of linguistic symbols. Sometimes, they even replace the linguistic symbols in social intercourse to express ideas and emotions that cannot be conveyed linguistically. These postures and movements which can communicate emotions and intentions are called body language."[1] "Human body language is a set of non-linguistic symbols which use human movements, facial expressions, boundary and costume as the tool to communicate information and emotions. It is a kind of voiceless language that uses forms to expressing meaning."[2] "People hold different viewpoints about how to define human body language in a scientific way." However, one viewpoint which have receives more agreement and acknowledgement is "human body language is meaningful symbols expressed by human actions, facial expressions, spatial distance, costume, and accessories." ${ }^{[3]}$

We hold that body language is "visual signals used in CLC No.: G40 Document Code: A people's social intercourse which include movements, postures, and facial expressions that communicate emotions, attitudes and auxiliary information."

About this definition, we need to clarify on the following points:

A. As not all the sounds made by people are called language, not all the movements, postures, facial expressions made by people are called body language

Only those movements, postures, facial expressions used in social intercourse have meaning and they can be called body language. People maintain postures or make movements at any time, some times these postures and movements are meaningless, or their meaning are irrelevant to social intercourse. For example, dance uses the dancer's body movements to unfold the story and express emotions, but dance is not body language because it is used for doing social intercourse. Study on body language must be conducted under this specific condition.

\section{B. The main purpose of body language is to communicate emotions and attitudes}

People have many ways to do social intercourse, like audible language (here we mean language in a narrow sense, namely the symbol system integrating voices and meaning, so as in the following context), and words, etc. However, every way has its own unique characteristics and functions. Body language is a set of visual symbols that are used mainly to communicate the speaker's moods, emotions and attitudes. It uses forms to convey feelings." According to foreign psychological statistics, people need 55\% human postures and movements, $38 \%$ sounds and only $7 \%$ verbal language to express their ideas and emotions. In other words, verbal language is mainly used to communicate information while body language is mainly used to communicate interpersonal attitudes.

C. The study of body language should focuses on postures, movements and facial expressions. Postures are static combinations of positions of different parts of the human body

Movements are postures on the move. Facial expressions are postures and movements of different facial organs in the head. Some people also treat spatial distance, costume and 
accessory as body language. If we say distance between people can be viewed as an extension of postures and movement, treating costume and accessory as body language will expand the denotation of body language without a justifiable reason, and it is not conductive to finding the common intrinsic properties of body language.

\section{ClASSIFICATION OF Body LANGUAGE}

We must classify body language in order to have a clear understanding of its characteristics.

There are a lot of studies conducted on classification of body language. For example, some people have classified it into three categories of active body language, passive body language and meaningless body language according to its effects. Some people also classify it into facial body language, hand body language and posture body language according to different human body parts that give the movements. The facial expressions can be further classified into expressions in the eyes and smiles; hand gestures into directive hand gestures, emotional hand gestures, simulative hand gestures and symbolic hand gestures; body postures into standing postures and walking postures.

According to different classifying standards, body language can be made into different categories. Everybody may have a justifiable to classify body language from different perspective. However, scientific classification of body language must guarantee the following points: firstly, the purpose of classification is to have a deeper understanding of characteristics of body language and to group body language with the same characteristics into one category while group body language with different characteristics into different categories. Thus we may know about characteristics of body language more thoroughly; secondly, just like classification of other things than body language, different categories of body language under the same standards cannot have overlap or negligence.

In this paper, we will classify body language into the following categories:

\section{A. Symbolic Body Language and Physiological Body Language}

Body language can be classified into symbolic body language and physiological body language according to properties of body language. Symbols referred here must have two basic characteristics: firstly they must have forms and meaning; secondly, there is no necessary connection between the form and the meaning. The connection is artificially bestowed in a random way. Verbal language is typically symbols while part of body language is symbols and part of it is not. Symbolic body language refers to the category of body language where there is no necessary relationship between the body positions (including postures, movements and facial expressions) and their meaning. For example, making a circle with the thumb and forefinger and straightening the other three fingers means "OK" to Americans and Parisians, while it means zero or having nothing to people living in southern France, "I'm going to kill you" to Tunisians, money to Japanese, and blasphemy to Brazilians.[4] Symbolic body language boasts distinctive cultural and temporal properties.
Physiological body language refers to the category of body language in which there is necessary relationship between body positions and their meaning. Inward emotions and moods like anger, happiness and hatred will trigger some physiological reactions that will be expressed by outward movements, postures and facial expressions. For example, people smile when they are happy and blush when they feel shy. Physiological body language is at the bottom body language because it is the most primitive and truthful. People may tell a lie by verbal language and symbolic body language, however, their physiological body language can betray it.

It is not discreet to say body language has cultural and temporal aspects and truthfulness. Classifying body language into symbolic body language and physiological body language can help us have a more precise knowledge of properties of body language.

\section{B. Dynamic Body Language and Static Body Language}

Body language can by classified into dynamic body language and static body language according to different states of participants in social intercourse. Dynamic body language refers to transition from one posture or facial expression to another, which is represented by movements of the limb or head. Emotions, attitudes and information will be communicated during the movements. Nodding heads and waving hands are examples of dynamic body language. As dynamic body language is actually body movement, some characteristics of movements like direction, intensity, frequency, speed, distance, etc become indispensable elements for body language to express meaning and for people to understand body language. Take nodding head as an example, intensity and range of the head-nodding movement may express different emotions. Description of dynamic language could not be done without give due attention to this point. Static body language is static postures and facial expressions. For example, a person sits in front of a desk, cross-legged, with both ankles locked together and the head tipped slightly to one side and a palm supporting the face. This is a static posture, which might express criticism, hatred or negation against the speaker in social intercourse, therefore, this static posture is static body language. In social intercourse, dynamic and static body language might be intermingled. People seldom maintain only a posture or keep moving ceaselessly.

Dynamic body language is continuous combination of one after another static body language. In other words, static body language is a freeze-frame of dynamic body language. Classification of body language into dynamic and static body language will facilitate description of body language.

\section{Auxiliary Body Language and Independent Body Language}

Body language can be classified into auxiliary body language and independent body language according to their functions. Auxiliary body language refers to the category of body language that exists on the basis of verbal language. It always expresses meaning in the context of verbal language communication or in corroboration with verbal language. Its feature is "auxiliaries". It will support, ornament verbal behaviors and strengthen expression of verbal behaviors. 
Independent body language refers to the category of body language that can express meaning independently of verbal language under specified circumstances. Sign language of traffic police and dumb and deaf people are examples of independent body language.

Language of deaf and dumb peoples are also called sign language, which uses in accordance with some grammar laws finger postures, hand movements, positions and directions in corroboration with facial expressions to communicate their specified meaning in the communicative context of deaf people. It uses hands to express the language, hand forms are the physical vehicle of the language. It uses the shape, position and movement of hands to communicate information. About sign language, some people think it is a kind of independent body language while some people think it is a kind of body language affiliated with verbal language. [5] In this paper we think sign language is kind of body language, it is a kind of independent body language that has a complete system and can express emotions and meaning independently.

Compared with dependent body language, independent body language has its peculiar features. Firstly, it has constraints. It is a kind of tacit understanding and customs among certain human groups. Users bestow specified meaning on hand gestures, which are widely acknowledged by them. Secondly, it shows society features as verbal language shows ethnicity features. Different human groups have different body language. For example, deaf and dumb people can use postures to communicate with and understand each other because they have the same psychological and physiological traits; traffic police form their directive sign language because there are common needs between police and pedestrians. Thirdly, independent body language has its relative complete system, therefore, it can communicate emotions and meaning independently.

\section{Body Language for specific occasions, Body Language for Regular Occasions}

Body language can be classified into body language for specific occasions and body language for regular occasions according to occasions where it can be used. Specific occasions refer to social avenues which have special purposes, specific people, time and space, for example teaching occasions, TV program avenues, business negotiation and marketing occasions, socializing occasions, etc. Body language used on a specific occasion is called body language for specific occasions. Because it is used for specific purposes, by specific characters, on specific time and space, body language for specific occasions usually have presupposition, namely it is decided beforehand which body language is used to communicate what emotions and attitudes for specific objects and purposes on specific occasions. For example, in a socializing avenue, the body language used by waiters to guests and that used among guests are different. These languages are formularized and people must follow them to express themselves and understand the other people. However, it is improper to use body language for a socializing occasion on a teaching avenue, because teaching has its own body language. Body language for regular occasion refers to the body language produced and used naturally by people in their daily socializing activities. The most distinctive feature of body language for regular occasions is naturalness. No people will intentionally design a special body language to express himself, because body language always displays strong concomitant features. Body language will show in a most natural way in the company of verbal language.

Body language for specific occasions is produced on basis of body language for regular occasions in accordance with places where it is used. It discards those improper and imprecise elements of body language for regular occasions and comes into being after refinement and instillation. For example, when people meet in daily life, they greet each other by nodding and bowing slightly. This is very natural. However, in a service avenue, the waiter must cross his hands in front and bowing his upper body to 45 degrees to welcome the guest.[6] Distinguishing between body language for specific occasions and body language for regular occasions will make us understand better how people create and use body language.

\section{COMMUNICATIVE CONTEXT OF BODY LANGUAGE}

As the vehicle of communication, body language is mainly used for expression and comprehension. The correct understanding and using of body language is conducive to the smooth progress of communication. Here the understanding of body language has been mainly discussed.

Only in the communication can the meaning of body language be revealed. Besides, the ideographical expression of body language is characterized by fuzziness, ambiguity, cultural sense, conventionality, etc. Therefore, to correctly understand the meaning of body language, we must put it in the communicative context which includes the following aspects.

\section{A. Posture group}

An integral whole made of several related postures, actions and expressions is called "posture group". Of which, each isolated body language is involved with the expression and constitutes the communicative context of other body languages, unable to be expressed separately, just part of what the whole posture group is expressing.

Just like verbal language, body language also consists of certain language units. Each gesture is like a word while each word may have multiple meanings. Only by putting the word in the sentence can we fully understand what it means. The sentence formed by posture groups will tell you a person's true feeling or attitude. People with perceptual skill have the ability to interpret someone else's non-linguistic sentence and accurately compare it with the linguistic sentence of such person.

Such as the common evaluative posture group which is composed primarily of the following postures: putting index finger on the cheek, pressing middle finger against the lips and supporting chin with the thumb. If it's a negative evaluation, we can also see: crossing both legs together, putting one arm across before the belly, slightly drooping the head and jaw. This non-linguistic sentence is probably saying: "I don't think your advice is correct and I don't agree with 
you". [7]

If a posture is viewed in isolation, it will be very difficult to determine the specific feeling it conveys. For instance, the clenched fist expresses an excited feeling. But why excited? Is it because of anger, happy, strong will or repression? To achieve correct judgment, we must combine with other factors.

Posture group is equivalent to the context as said in verbal language.

\section{B. Verbal language context}

Based on its functions as mentioned before, the body language is divided into auxiliary body language and independent body language. The independent body language is used by certain groups in the specific environment while the auxiliary body language exists in the verbal communication of ordinary people. Since the auxiliary body language is always appearing with the verbal language, the verbal language has become the communicative context of body language (mainly auxiliary body language). The body language cannot be comprehended without verbal language.

In fact, body language and verbal language are communicative contexts to each other. On the one hand, the verbal language sometimes cannot be comprehended without body language (body language is more helpful in grasping speaker's feeling and attitude), such as "Great! You kid", in different body language contexts, this sentence has different meanings. If someone gives thumbs-up sign, bends over and nods his head, he is probably expressing admiration; if someone beats the table with hands, staring, he is probably expressing anger; if someone looks sideways and folds his arms, he is probably expressing contempt. On the other hand, the meaning of body language will be clearer in linguistic context. Such as the action "nodding" which often represents affirmative attitude, but approval of what is unclear, which will be explicit if placed in the linguistic context: if someone asks whether you are hungry, then nodding means "yes, I'm hungry"; if someone asks whether you want to go for a trip, then nodding means "yes, I want to go for a trip".

Normally, people tend to intentionally or unintentionally use body language to help the expression of verbal language, and the two complement each other. However, sometimes, the body language will be inconsistent with and deviate from verbal language when someone speaks insincerely. Research has shown that: in case of inconsistency, people always choose body language information over verbal language information. The reason for this is that body language itself is able to convey certain meaning, and for the expression of feelings and attitudes, the weight of body language is five times larger than that of verbal language.

\section{Social context}

For the physiological body language arising from physiological changes, all normal people will have the same reaction under the same situation, which can be directly perceived. While specific to the conventional body language, just like the understanding of verbal language, it cannot be comprehended without social context.
The social context refers to the concrete occasion and social background of communication, specifically including: both sides of communication and their relationship, such as the communicator's status, personality, both sides' rank, gender, nationality, etc.; communicative occasions, such as chat, debate, negotiation, speech, reception, etc.; purposes of communication, such as appreciation, apology, commitment, command, etc.; communicative era, cultural background, etc. All these factors interact on each other, jointly promoting the realization of communication. Both languages, either verbal language or body language, cannot obtain the specific meaning until they are placed in the concrete context. In communication, to correctly and fully understand the expresser's meaning, we must lay emphasis on the social context.

As we said, the spatial distance between communicators is a body language which indicates the affection between the two sides. But how far shall it represent "intimacy" and how far shall it represent "aversion"? It is quite vague and can be determined only by combing with the above context. In cross-cultural communication, both sides often use body language for expression. Since with different cultural backgrounds, there may be different understandings for the same posture or action; only standing on the other side's culture context can we accurately understand the expression meaning and ensure the smooth progress of communication.

\section{CONCLUSION}

This paper has mainly discussed the classification of body language and communicative context. Characterized by abundance and complexity, the body language presents different features which, along with its nature, can be precisely recognized only via classified study. Without doubt, the body language can be divided into different categories according to different classification criterion, while the classification of body language in this paper is guaranteed systematic and scientific as far as possible. For the understanding of body language, just like that of verbal language, it must be done in the specific communicative context. The communicative context of body language shares some similarities with that of verbal language but also has its own characteristics. The meaning of body language not only depends on the specific posture, action and expression but also depends more on the posture group to which it belongs, accompanying verbal language and social context at the time of communication.

\section{REFERENCES}

[1] Kuang Xinhua, Comparative Study on Body Language and Linguistic Language [J], Nanchang, Journal of Nanchang Institute of Aeronautical Technology (Social Science), 2000 (12) 76-77.

[2] Lei Tao, Introduction to Body Language [J], Journal of Southwest University for Nationalities (Philosophy and Social Science), 2001 (11) 178-180.

[3] Meng Zhaoquan, Discussion on the Characteristics of Body Language [J], Journal of Henan University (Social Science), 2006 (2) 108-112.

[4] Jiang Chunqing, Deng Yong, Body Language and Communication [J], Journal of Guangxi Normal University, 1990 (3) 85-87. 
[5] He Wenming, Discussion on the Linguistic Characteristics of Sign Language [J], Modern Special Education, 1995 (11) 56-58.

[6] Jin Zhengkun, Social Etiquette [M], Beijing, Peking University Press, Jul. 2006.

[7] Wrote by Allan Pease, translated by Jia Zongyi, Body Language [M], Beijing, Xinhua Publishing House, Aug. 2002. 